\title{
Possible role of nutritional priming for early salt and drought stress responses in Medicago truncatula
}

\author{
Christiana Staudinger ${ }^{\dagger}$, Vlora Mehmeti $^{\dagger}{ }^{,}$Reinhard Turetschek, David Lyon, Volker Egelhofer and \\ Stefanie Wienkoop*
}

Department of Molecular Systems Biology, University of Vienna, Vienna, Austria

Edited by:

Dominique Job, Centre National de la

Recherche Scientifique, France

\section{Reviewed by:}

Roque Bru-Martinez, Universidad de

Alicante, Spain

Jean-Michel Ané, University of

Wisconsin-Madison, USA

${ }^{*}$ Correspondence:

Stefanie Wienkoop, Department of

Molecular Systems Biology,

University of Vienna, Althanstrasse

14, 1090 Vienna, Austria.

e-mail: stefanie.wienkoop@

univie.ac.at

${ }^{+}$Christiana Staudinger and Vlora

Mehmeti have contributed equally to

this work.
Most legume species establish a symbiotic association with soil bacteria. The plant accommodates the differentiated rhizobia in specialized organs, the root nodules. In this environment, the microsymbiont reduces atmospheric nitrogen $(\mathrm{N})$ making it available for plant metabolism. Symbiotic N-fixation is driven by the respiration of the host photosynthates and thus constitutes an additional carbon sink for the plant. Molecular phenotypes of symbiotic and non-symbiotic Medicago truncatula are identified. The implication of nodule symbiosis on plant abiotic stress response mechanisms is not well understood. In this study, we exposed nodulated and non-symbiotic $\mathrm{N}$-fertilized plants to salt and drought conditions. We assessed the stress effects with proteomic and metabolomic methods and found a nutritionally regulated phenotypic plasticity pivotal for a differential stress adjustment strategy.

Keywords: salt stress, plant-microbe interactions, drought stress, Medicago truncatula, mapman mapping

\section{INTRODUCTION}

Reduced water availability will dramatically impact agricultural productivity in the next 40 years. According to demographic and climate change models, the human population will double by 2050 and the variability in rainfalls will increase (IPCC, 2007). Therefore, we need a profound understanding of plant physiology and metabolism under water limiting conditions.

Drought and salinity are environmental constraints accounting for substantial yield losses. Both decrease the amount of water available to plants, leading to reduced growth, and photosynthesis (Chaves et al., 2009). Thus, it has been proposed that early acclimatory responses to both stresses share strong commonalities (Munns, 2002).

Legumes play an important role in increasing the sustainability of agricultural land use. Amongst several studies on drought and salt stress effects in model legumes, many have been conducted with Medicago spp. recently (Lopez et al., 2008; Bianco and Defez, 2009; Salah et al., 2009; Aranjuelo et al., 2011; Filippou et al., 2011; Kang et al., 2011). Noticeably, the symbiotic status amongst the studies is very diverse. The stress response of $\mathrm{N}$-fixation in root nodules was extensively studied (Larrainzar et al., 2007, 2009; Naya et al., 2007; Lopez et al., 2008; Salah et al., 2009). However, various

Abbreviations: C, control; D, drought; DW, dry weight; $F^{\prime}$, chlorophyll fluorescence in the light-adapted state; FDR, false discovery rate; $F_{\mathrm{m}^{\prime}}$, chlorophyll fluorescence when PSII centers are maximally closed in the light-adapted state; $F_{\mathrm{q}^{\prime}}$, difference between $F^{\prime}$ and $F_{\mathrm{m}^{\prime}} ; \mathrm{FW}$, fresh weight; $g_{\mathrm{s}}$, stomatal conductance; IS, internal standard; N, nitrogen; $\mathrm{N}$-fed, nitrogen fertilization; $\mathrm{N}$-fix, nitrogen fixation; PS, photosynthesis; PSII, photosystem II; S, salt; SE, standard error; WC, water content; $\Psi_{\text {leaf }}$, leaf water potential. publications have been conducted with non-symbiotic (not inoculated with rhizobia) legumes (Sanchez et al., 2008a; Noreen and Ashraf, 2009; Diaz et al., 2010). Interestingly, a positive impact of rhizobial symbiotic interaction to stress has been proposed (Frechilla et al., 2000; Miransari and Smith, 2009). However, the influence of symbiotic interactions on abiotic stress acclimatory mechanisms is still in its infancy.

During their life-cycle plants acclimate to environmental constraints by a wide range of mechanisms that are conceptually classified as avoidance or tolerance strategies (Levitt, 1980). In case of lowered water availability in the environment, stress avoidance essentially aims at maintaining the initial plant water status and lowering the rate of stress imposed at the tissue or cellular level. Tolerance strategies aim at preventing damage and maintaining metabolism, once water deficit has been established. Avoidance and tolerance mechanisms are neither mutually exclusive nor active in a temporal sequence. Their distinction is conceptual, but useful when investigating plant stress responses (Verslues et al., 2006).

Plant acclimatory responses are complex exhibiting multigenic and interrelated properties. In addition, comparability with previous work is known to be hampered, due to heterogeneities in factors influencing stress responses such as plant age, growth conditions, diurnal changes, and the experimental treatment, such as severity, duration, and method of stress imposition (Aguirrezabal et al., 2006). Consequently, robust parameters for a specific definition of stress are still missing. Due to the complexity of plant stress response and its interlinked mechanisms and influencing factors, it becomes necessary to extend research to multilevel analyses (Jogaiah et al., 2012). Using systems biology approaches the integration 
of -omics data such as metabolomics and proteomics may also compensate method specific limitations.

To date, data of proteomic studies are still behind in numbers of identifications that of transcript data. Nevertheless, the informative value on the protein level seems high for several reasons. For instance, the direct translation of transcript abundance to protein abundance in terms of one point abundance and changes over time is still under controversial debate. Especially, in the context of changes in time- and stress dependent manner it has been shown that transcript and protein data do not correlate significantly (Hajduch et al., 2010). As a possible reason they suggest for instance regulation via post-translational protein modification. A temporal lag that causes, e.g., a delay in adjustment of enzyme abundance when transcript levels have already changed, have extensively been discussed by Gibon et al. (2004, 2006).

So far, most studies focused on genetic engineering using, e.g., Quantitative Trait Loci (QTL) mapping have shown only limited success (Rispail et al., 2010). Thus, knowledge transfer from transcript and genome data complemented with postgenomic metabolite and proteome data will enhance the success for smart breeding in future.

In the present study, early stress response mechanisms to salt and drought stress have been investigated. The aim of this work was to (i) unravel robust and easily detectable putative stress response markers on a physiological, metabolite as well as protein level and (ii) to find novel insights for a regulatory relevant role of the nutritional priming comparing shoots of $\mathrm{N}$-fixing with fertilized M. truncatula plants.

\section{MATERIALS AND METHODS PLANT GROWTH AND SAMPLING CONDITIONS}

The seeds of barrel medic ( $M$. truncatula A17 cv. Jemalong) were surface sterilized and sown in pots containing a mixture of perlite:vermiculite 2:5 (v:v). The experimental setup was based on the protocol used by (Larrainzar et al., 2009). Plants were grown under controlled conditions in a growth chamber (14-h day and 10-h night; $270 \mu \mathrm{mol} \mathrm{m}^{-2} \mathrm{~s}^{-1}$ photosynthetic photon flux density; $22^{\circ} \mathrm{C}$ day and $16^{\circ} \mathrm{C}$ night temperatures; $50-60 \%$ relative humidity). During the first week of growth, plants were watered with nutrient solution (Evans, 1981) containing $0.5 \mathrm{mM}$ ammonium nitrate. The following 2 weeks a nutrient solution with ammonium nitrate concentration of $2.5 \mathrm{mM}$ was used for watering in order to enhance biomass accumulation and to keep plant growth performance identical during the initial developmental stage. After 3 weeks, half of the plants were randomly selected and inoculated with S. meliloti 2011. Furthermore, for inoculated plants nutrient solution was $\mathrm{N}$ free while the other subset was fertilized with $2.5 \mathrm{mM}$ ammonium nitrate. After 7 weeks plants were randomly separated into sub-sets: control and drought or salt stressed, respectively. Control plants were supplied daily with nutrient solution to pot capacity whereas abiotic stress was applied to the other groups as follows. Drought stress was imposed by withholding water and nutrients; after flushing pots with deionized water, nutrient solutions containing $200 \mathrm{mM} \mathrm{NaCl}$ were applied every day to salt stressed plants. After 6 days of stress, plants were harvested $6 \mathrm{~h}$ after the onset of light. M. truncatula shoot and root tissue was separated, flash-frozen in liquid nitrogen, and stored at $-80^{\circ} \mathrm{C}$ until further processing. Analysis was carried out as previously described using 3 biological replicates for each condition: $\mathrm{N}$-fertilized and inoculated plants [ $n$ the following referred to as $\mathrm{N}$-fed and nitrogen fixing ( $\mathrm{N}$-fix)] exposed to salt stress or water deprivation as well as control without stress treatment.

\section{PHYSIOLOGICAL PARAMETERS}

Stomatal conductance $\left(g_{\mathrm{s}}\right)$ was measured $3 \mathrm{~h}$ after onset of the photoperiod with a steady-state porometer (PMR-4, PP Systems, Hitchin, UK) connected to the EGM-4 gas monitor serving as data logger. About $0.5 \mathrm{~cm}^{2}$ of terminal leaflets of fully expanded leaves were placed into a cuvette. Records were taken after $\sim 20 \mathrm{~s}$, when equilibrium was established. The inlet air flow rate was kept constant at $75 \mathrm{ml} / \mathrm{min}$. The porometer then measured the air humidity of inlet and outlet air flow, air temperature and the PPFD reaching the leaf. From these parameters $g_{s}$ was calculated. The water content (WC) of the leaves and roots was calculated as $(\mathrm{FW}-\mathrm{DW})^{*} \mathrm{FW}^{-1}(\mathrm{FW}=$ fresh weight; $\mathrm{DW}=$ dry weight $)$. Leaf water potential was measured $3 \mathrm{~h}$ after the onset of the photoperiod with a Scholander pressure bomb. Primary chlorophyll fluorescence parameters $\left(F_{\mathrm{m}^{\prime}}, F^{\prime}\right)$ were assessed employing a saturation pulse method, using the MINI-head version of the IMAGING-PAM chlorophyll fluorometer M-series (Heinz Walz $\mathrm{GmbH}$, Effeltrich, Germany). The PSII operating efficiency was calculated by $F_{\mathrm{q}}{ }^{\prime} / F_{\mathrm{m}^{\prime}}=\left(F_{\mathrm{m}}{ }^{\prime}-F^{\prime}\right) / F_{\mathrm{m}}{ }^{\prime}$ (Baker, 2008). Analysis was carried out on three biological replicates for each of the previously described conditions (Table 1).

\section{EXTRACTION AND DERIVATIZATION OF METABOLITES}

Medicago truncatula roots and shoots were ground to a fine powder under liquid nitrogen and subsequently lyophilized. About 10 and $30 \mathrm{mg}$ of the powdered shoots and roots were used for the extraction with $1 \mathrm{ml}$ of freshly prepared and pre-cooled extraction buffer ( $\mathrm{MeOH}: \mathrm{CHCl}_{3}: \mathrm{H}_{2} \mathrm{O}, 2.5: 1: 0.5$ ), respectively. In order to avoid any degradation or modification of metabolites the samples were kept on ice for $8 \mathrm{~min}$. During this time the samples were vortexed

Table 1 | Effect of drought and salt treatments on plant water status and physiological parameters in $\mathrm{N}$-fed (A) and $\mathrm{N}$-fix (B) M. truncatula.

Parameter Control Drought Salt

\begin{tabular}{lccr}
\hline (A) N-FED & & & \\
$\mathrm{WC}_{\text {shoot }}$ & $0.82 \pm 0.06 \mathrm{a}$ & $0.78 \pm 0.01 \mathrm{~b}$ & $0.82 \pm 0.01 \mathrm{a}$ \\
$\Psi_{\text {leaf }}(\mathrm{MPa})$ & $-0.68 \pm 0.07 \mathrm{a}$ & $-1.06 \pm 0.08 \mathrm{~b}$ & $-0.69 \pm 0.18 \mathrm{a}$ \\
$g_{\mathrm{s}}\left[\mathrm{mmol} \mathrm{m}{ }^{-2} \mathrm{~s}^{-1}\right]$ & $381.52 \pm 139.02 \mathrm{a}$ & $121.52 \pm 30.32 \mathrm{~b}$ & $37.01 \pm 5.46 \mathrm{c}$ \\
$F^{\prime}{ }_{\mathrm{q}} / F^{\prime} \mathrm{m}$ & $0.55 \pm 0.05 \mathrm{a}$ & $0.44 \pm 0.07 \mathrm{~b}$ & $0.58 \pm 0.03 \mathrm{a}$ \\
(B) N-FIX & & & \\
$\mathrm{WC}_{\text {shoot }}$ & $0.89 \pm 0.01 \mathrm{a}$ & $0.89 \pm 0.01 \mathrm{a}$ & $0.90 \pm 0.01 \mathrm{a}$ \\
$\Psi_{\text {leaf }}(\mathrm{MPa})$ & $-0.73 \pm 0.10 \mathrm{a}$ & $-0.98 \pm 0.09 \mathrm{~b}$ & $-0.75 \pm 0.17 \mathrm{a}$ \\
$g_{\mathrm{s}}\left[\mathrm{mmol} \mathrm{m}{ }^{-2} \mathrm{~s}^{-1}\right]$ & $425.95 \pm 156.23 \mathrm{a}$ & $165.71 \pm 36.15 \mathrm{~b}$ & $36.14 \pm 6.40 \mathrm{c}$ \\
$F^{\prime}{ }_{\mathrm{q}} / F^{\prime}{ }_{\mathrm{m}}$ & $0.57 \pm 0.02 \mathrm{a}$ & $0.56 \pm 0.01 \mathrm{a}$ & $0.58 \pm 0.02 \mathrm{a}$ \\
& & &
\end{tabular}

Values represent the mean $\pm S E(n=3)$. The letters $a, b$, and $c$ indicate significant differences between control and stress treatments (Student's t test $p<0.05$ ). $W C$, water content; $\Psi_{\text {leaf, }}$ leaf water potential; $g_{s}$, stomatal conductance; $F_{q} / F_{m}$, PSIl operating efficiency. 
regularly and afterward centrifuged for $4 \mathrm{~min}$ at $14,000 \mathrm{~g} / \mathrm{min}$, at $4^{\circ} \mathrm{C}$. The supernatant was added to another tube which contained $500 \mu \mathrm{l}$ of ultrapure water and shaken thoroughly. After the phase separation by centrifugation ( $4 \mathrm{~min}, 14,000 \mathrm{~g} / \mathrm{min}$ ), the upper polar phase was split into two aliquots. Internal standard (IS) was added $\left(10 \mu \mathrm{l}\right.$ of $0.1 \mathrm{~g} / \mathrm{l}^{13} \mathrm{C}_{6}$-Sorbitol) and the samples were dried out using a vacuum concentrator at room temperature. For metabolite derivatization, $20 \mu \mathrm{l}$ of the freshly prepared methoximation mixture $(40 \mathrm{~g} / \mathrm{l}$ methoxyamine hydrochloride $\mathrm{CH}_{3} \mathrm{ONH}_{2}{ }^{*} \mathrm{HCL}$ in pyridine) were added to the dried samples and shaken for $90 \mathrm{~min}$ at $30^{\circ} \mathrm{C}$. After adding $80 \mu \mathrm{l}$ of the silylation mixture: $1 \mathrm{ml}$ of MSTFA ( $N$-methyl- $N$-trimethylsilyl trifluoroacetamide) spiked with $30 \mu \mathrm{l}$ of the alkane standard mixture (C10-C40, each $50 \mathrm{mg} / \mathrm{l})$ as retention index (RI) marker, the samples were incubated for $30 \mathrm{~min}$ with shaking at $37^{\circ} \mathrm{C}$ and then centrifuged $(14,000 \mathrm{~g} / \mathrm{min})$ for $2 \mathrm{~min}$ to remove any insoluble material. The supernatant was carefully taken and transferred into glass vials with micro inserts. One microliter of the derivatized sample was injected. Six replicates per treatment (three biological, two technical) were randomly injected to discriminate technical from biological variation.

\section{GC-TSQ-MS SETTINGS}

For metabolite profiling GC-MS is mostly the method of choice. Here we used GC hyphenated to triple quadrupole (Thermo Scientific TSQ Quantum GC ${ }^{\mathrm{TM}}$, Bremen, Germany). In order to identify a large number of metabolites, a profiling analysis in full-scan mode was performed with a scan range of $\mathrm{m} / \mathrm{z} 40-600$ and a scan time of $200 \mathrm{~ms}$. The metabolite separation was performed on a HP-5MS capillary column $(30 \mathrm{~m} \times 0.25 \mathrm{~mm} \times 0.25 \mu \mathrm{m}$; Agilent Technologies, Santa Clara, CA, USA), at a constant flow $1 \mathrm{ml} / \mathrm{min}$ helium. The split less injection of $1 \mu \mathrm{l}$ of the sample was done by the TriPlus auto sampler (Thermo Scientific, Bremen, Germany). The temperature of the injector was $230^{\circ} \mathrm{C}$. Compound elution settings were $1 \mathrm{~min}$ at $70^{\circ} \mathrm{C}$ isotherm, ramp to $76^{\circ} \mathrm{C}$ at $1^{\circ} \mathrm{C}$ per min heating rate, then to $350^{\circ} \mathrm{C}$ at a $6^{\circ} \mathrm{C}$ per min rate and hold for $1 \mathrm{~min}$. Post run temperature was set to $325^{\circ} \mathrm{C}$ for $10 \mathrm{~min}$. The transfer line temperature was set to $340^{\circ} \mathrm{C}$ and ion source temperature was $250^{\circ} \mathrm{C}$. Electron Impact (EI) ionization was set to $70 \mathrm{eV}$.

\section{METABOLITE DETECTION, IDENTIFICATION, AND RELATIVE QUANTIFICATION}

The criteria used for identification were fragmentation patterns that are characteristic for the particular compound, the retention time (RT) and RI. Combining these criteria, it is possible to unambiguously identify metabolites and distinguish between the components even if they are chemically very similar. The identification of each analyte was achieved by matching the MS-spectra and RT against (a) an in-house library (modified gmd database) ${ }^{1}$; (b) AMDIS (calculation of retention indices and comparison with RI of compounds in the mass spectral library); and (c) matching against the in-house measured standards. Calculation of retention indices was performed using the RT of the detected compound and the RT of the RT-index marker (alkane mixture), calculated with

\footnotetext{
${ }^{1}$ http://gmd.mpimp-golm.mpg.de/download/
}

AMDIS for representative samples of different treatments. Due to derivatization, in some cases more than one peak was detected for one metabolite. These peaks were initially analyzed separately and summed up for further analysis or data mining. About $15 \%$ of the detected analytes were identified as unknown compounds. Calculation of the peak areas was performed using LC-Quan for the GC-TSQ-MS data, which is suitable to calculate the peak area for all compounds in all samples according to given parameters. Here the determined RT as well as the quant mass for each component was used to automatically extract data from all sample replicates. An initial data matrix of the calculated peak area for each detected compound was obtained separately. The list of detected components and calculated areas was exported to an Excel file. We used an in-house Matlab tool to produce a complete data matrix automatically. The data matrix was normalized to the sample DW and the IS for relative quantification.

\section{PROTEIN EXTRACTION}

The same three biological replicates as those taken for metabolite analysis have been used for protein extraction. Two hundred milligrams of liquid nitrogen frozen shoot material were cryoground using a Retsch MM400 ball mill and homogenized in $1 \mathrm{ml}$ of urea buffer containing $50 \mathrm{mM}$ HEPES, pH 7.8, $5 \mathrm{mM}$ PMSF, and $8 \mathrm{M}$ Urea. After centrifugation $\left(10,000 \mathrm{~g}, 10 \mathrm{~min}, 4^{\circ} \mathrm{C}\right)$ the urea soluble proteins in the supernatant were precipitated overnight in five volumes of $-20^{\circ} \mathrm{C}$ cold acetone containing $0.5 \%$ $\beta$-mercaptoethanol. The precipitate was pelleted at $4,000 \mathrm{~g}, 4^{\circ} \mathrm{C}$ for $15 \mathrm{~min}$. The resulting pellet was washed with $-20^{\circ} \mathrm{C}$ cold methanol and again centrifuged $\left(4,000 \mathrm{~g}, 4^{\circ} \mathrm{C}, 10 \mathrm{~min}\right)$.

\section{PROTEIN DIGESTION}

Air-dried protein pellets were dissolved in $500 \mu \mathrm{l}$ urea buffer the protein concentration was determined by Bradford assay, using BSA as a standard. $100 \mu \mathrm{g}$ of protein was initially digested using endoproteinase LysC (1: $100 \mathrm{vol} / \mathrm{vol}, 5 \mathrm{~h}, 30^{\circ} \mathrm{C}$, Roche, Mannheim, Germany). For the second digestion step, samples were diluted with trypsin buffer ( $\left.10 \% \mathrm{ACN}, 50 \mathrm{mM} \mathrm{AmBic,} 2 \mathrm{mM} \mathrm{CaCl}_{2}\right)$ to a final concentration of $2 \mathrm{M}$ Urea and incubated overnight at $37^{\circ} \mathrm{C}$ with Porosyzme immobilized trypsin beads (1:10, vol/vol; Applied Biosystems, Darmstadt, Germany). The digest was desalted with C18-SPEC 96- well plates (Varian, Darmstadt, Germany) according to the manufacturer's instructions. The eluted peptides were vacuum-dried.

\section{nanoESI LC-MS/MS}

Peptide digests $(0.5 \mu \mathrm{g}$ each) were randomly applied to a RP monolithic capillary column $(50 \mu \mathrm{m}$ internal diameter, $15 \mathrm{~cm}$ length, Merck, Darmstadt, Germany) separated during a $120 \mathrm{~min}$ gradient ranging from $90 \%$ solvent $\mathrm{A}(0.1 \% \mathrm{FA}$ in water) to $80 \%$ solvent B ( $80 \%$ acetonitrile, $0.1 \%$ FA in water). For each treatment tree biological and three technical replicates were randomly analyzed. MS analyses were performed on a LTQ-Orbitrap XL (Thermo Fisher Scientific, Bremen, Germany). For the database dependent spectral count analysis (Wienkoop, 2011), a top five MS analysis setting was used with the full-scan range from 350 to $1,800 \mathrm{~m} / \mathrm{z}$. Dynamic exclusion settings were as described in Hoehenwarter and Wienkoop (2010). Briefly, repeat count was set to 
one, repeat duration $20 \mathrm{~s}$, exclusion list size 500, exclusion duration $60 \mathrm{~s}$ and exclusion mass width $10 \mathrm{ppm}$. Charge state screening was enabled with rejection of unassigned and $1+$ charge states. Minimum signal threshold counts were set to 1,000 .

\section{PROTEIN IDENTIFICATION AND RELATIVE QUANTIFICATION}

We used the SEQUEST algorithm and the Proteome Discoverer (v 1.3, Thermo Scientific) to search MS data against a fasta file we created from a Medicago spp. and Sinorhizobium spp. subset of UniProt Knowledgebase ${ }^{2}$ containing 63,688 sequences as of April 2012. In silico peptide lists were generated with the following settings: trypsin as the digestion enzyme, a maximum of three missed cleavages and methionine oxidation as dynamic modification. Mass tolerance was set to $5 \mathrm{ppm}$ for precursor ions and $0.8 \mathrm{Da}$ for fragment ions. Additionally, a decoy database containing reversed sequences was used to estimate the false discovery rate (FDR) Only high confidence (FDR $\leq 0.01 \%$ ) peptide identifications with a minimum XCorr of 2.2 and proteins with at least two distinct peptides were considered. Peptide spectra are stored in the ProMEX library (Wienkoop et al., 2012) and can be checked under its ID "Med trun001." Protein relative quantification is based on database dependent spectral counting as described previously (Larrainzar et al., 2009). Six replicates per treatment (three biological, two technical) were randomly injected to discriminate technical from biological variation.

\section{STATISTICAL ANALYSIS}

Detailed analysis of the physiology, as well as metabolite and protein data was performed by calculating the ratios between control and treated samples. Significant differences between these were determined using Student's $t$ test at $p<0.05$ and fold change $\geq 2$ (Tables 2 and 3 ).

${ }^{2}$ http://www.uniprot.org/

\section{MAPMAN MAPPING FILE FOR M. TRUNCATULA PROTEINS AND METABOLITES}

A new Mapman mapping file was created on the basis of the mapping file "Mt_Mt3.5_0411" and "MappingMetabolites" acquired from http://mapman.gabipd.org/web/guest/mapmanstore. This mapping file corresponds to MTGI release "Mt3.5v3 RELEASE 20100825” (“Mt3.5_GenesProteinSeq_20100825.fasta” subsequently called MTGI-fasta-DB) which can be found at http://www.jcvi.org/. Shotgun proteomics experimental data were evaluated with the Uniprot database fasta file (see Protein Identification and Relative Quantification).

The "Identifier" and "Description" categories of entries from the "Mt_Mt3.5_0411" mapping file correspond to accession numbers and header information of the MTGI-fasta-DB. The mapping file "Med trun_mappingformapman_Mosys_v1_20120913.txt" was created by comparing the protein sequences of the Uniprot-fastaDB (MT only) to the MTGI-fasta-DB. Comparison was performed using string comparison (unpublished Python script) as well as standalone BLAST from http://blast.ncbi.nlm.nih.gov. Mapping file entries corresponding to completely identical sequences were replaced. The "Bincode" and "Name" remained unchanged, but the "Identifier" and the "Description" were replaced by the corresponding Uniprot accession number and header, furthermore the "Type" was set to "P." All Uniprot entries not $100 \%$ identical in sequence and length to an entry in MTGI were blasted against a database created from the entire MTGI fasta file. Uniprot entry hits with an $e$-value equal to or lower than $10^{-3}$ replaced mapping file entries as previously described. Uniprot entry hits with $e$-values higher than $10^{-3}$ were added to the bincode "35.2.1" with the name "not assigned.unknown.evalhigh" and entry hits resulting in no query hit at all were assigned to the bincode "35.2.2" with the description "not assigned.unknown.blastwithouthits." The pertinent information of the metabolite mapping file from the MapMan Store was incorporated into the current mapping file by simply adding the respective entries (at the proper bin location). Certain entries were manually curated and shifted from "not assigned.unknown” bins to appropriate categories. Six metabolites

Table 2 | Ratios of stress responsive root metabolites (stressed/control).

\begin{tabular}{lllll}
\hline & SN-fed vs.CN-fed & SN-fix vs.CN-fix & DN-fed vs. CN-fed & DN-fix vs.CN-fix \\
\hline GABA & $3.1(0.019)$ & $0.5(0.046)$ & $\mathrm{ns}$ & $2.0(0.043)$ \\
Aspartate & $3.7(0.011)$ & $3.3(0.048)$ & $2.5(0.049)$ & $2.8(0.008)$ \\
Leucine & $2.0(0.007)$ & $\mathrm{ns}$ & $2.5(0.005)$ & $\mathrm{ns}$ \\
Threonate & $3.0(0.046)$ & $2.9(0.048)$ & $\mathrm{ns}$ & $2.8(0.001)$ \\
Glutamate & $4.9(0.024)$ & $\mathrm{ns}$ & $2.0(0.001)$ & $\mathrm{ns}$ \\
Proline & $\mathrm{ns}$ & $\mathrm{ns}$ & $10.5(0.001)$ & $12.1(0.005)$ \\
Fumarate & $3.5(0.025)$ & $2.3(0.004)$ & $3.1(0.001)$ & $3.3(0.009)$ \\
Galactonate & $3.8(0.001)$ & $2.8(0.013)$ & $\mathrm{ns}$ & $2.8(0.001)$ \\
Sucrose & $2.7(0.003)$ & $4.4(0.006)$ & $2.3(0.002)$ & $2.1(0.003)$ \\
Myo-Inositol & $4.0(0.003)$ & $\mathrm{ns}$ & $\mathrm{ns}$ & $2.0(0.001)$ \\
Ononitol & $3.0(0.035)$ & $2.0(0.003)$ & $3.0(0.018)$ & $\mathrm{ns}$ \\
Pinitol & $2.6(0.048)$ & $\mathrm{ns}$ & &
\end{tabular}

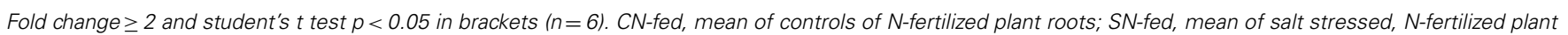
roots; $\mathrm{CN}$-fix, mean of controls of $\mathrm{N}$-fixing plant roots; $\mathrm{DN}$-fix, mean of salt stressed, $\mathrm{N}$-fixing plant roots; $n$ s, not significantly changed. 
Table 3 | Stress responsive shoot proteins and metabolites of six replicates as fold change.

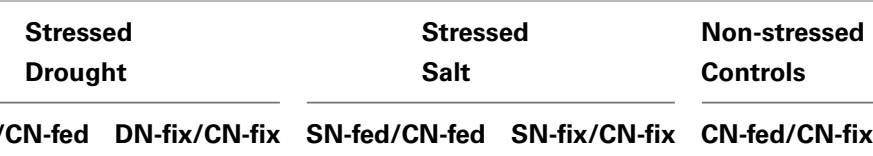

\section{PROTEINS}

1. Photosystem (PS)

1.1 PS.lightreaction

$\mathrm{N}-\mathrm{fed} / \mathrm{CN}-\mathrm{fed}$

CN-fed/CN-fix

G7IJ45 photosystem II 10 kDa polypeptid

G7JH56 photosystem II CP47 chlorophyll apoprotein

G7JE46 thylokoid luminal $16.5 \mathrm{kDa}$ protein

G7JAX6 photosystem I reaction center subunit $\mathrm{N}$

G7JQA7 apocytochrom $f$

B7FIU4 ATP synthase gamma chain

B7FIR4 ATP synthase gamma chain

G7JAI2 ATP synthase

1.2 PS.photorespiration

G7JAR7 serin hydroxymethyltransferase

1.3 PS.calvin cycle

G7J252 ribulose bisphosphate carboxylase small chain

2.1.2 Major CHO metabolism.synthesis.starch.transporter

G7LDP4 ADP, ATP carrier protein

3.4 Minor CHO metabolism.myo-inositol

G7J4B5 I-myo-inositol-1 phosphate synthase

G7LAD5 I-myo-inositol-1 phosphate synthase

6.3 Gluconeogenesis.Malate DH

G7JTZO Malate dehydrogenase

7.1 OPP.oxidative PP.6-phosphogluconate dehydrogenase

Q2HVD9 6-phosphogluconate dehydrogenase

9.9 Mitochondrial electron transport/ATP synthesis.F1-ATPase

G7LCJ4 ATP synthase delta subunit

10.1 Cell wall.precursor synthesis

G7L571 UDP-glucose 6-dehydrogenase

11.1 Lipid metabolism.FA synthesis and FA elongation

G7LIV6 biotin carboxylase

G7JNN1 Acyl-[acyl-carrier-protein] desaturase

11.6 Lipid metabolism.lipid-transfer proteins

G7JID0 non-specific lipid-transfer protein

ns

Q2HW53 ferredoxin-dependent glutamate synthase

P04078 glutamine synthetase cytosolic isozyme

13.1 Amino acid metabolism.synthesis

Q6J9 $\times 6$ SAMS

A4ULF8 SAMS

A4PU48 SAMS

G7L3W1 SAMS

G7JTY4 LL-diaminopimelate aminotransferase

G7J013 alanine glyoxylate aminotransferase

15.2 Metal handling.binding, chelation, and storage

G7K283 ferritin

G7JLS7 ferritin

16.2 Secondary metabolism.phenylpropanoids

G7JTH6 caffeic acid 3-O-methyltransferase ns

ns

ns

ns

$0.3(0.0029)$

ns

ns

ns

.

ns

ns

$5.3(0.0001)$

$2.0(0.0204)$

ns

$2.5(0.0001)$

ns

ns

ns

$2.5(0.002)$

ns

$\begin{array}{llll}\text { ns } & \text { ns } & 3.8(0.002) & n s \\ \text { ns } & 2.2(0.005) & n s & n s \\ \text { ns } & n s & 0.4(0.009) & n s \\ 0.3(0.029) & n s & n s & 2.9(0.043) \\ \text { ns } & n s & n s & n s \\ 2.8(0.003) & n s & n s & 0.5(0.010) \\ 0.5(0.009) & n s & n s & n s \\ \text { ns } & 3.5(0.0030) & n s & n s\end{array}$

$0.5(0.019) \quad n s \quad n s \quad n s$

ns $\quad 3.3(0.020) \quad n s(0.005)$

ns $\quad 2.1(0.014) \quad$ ns ns

ns ns $\quad 4.0(0.033)$

ns

ns ns

$0.4(0.000)$

$0.5(0.001) \quad$ ns $\quad$ ns $2.0(0.001)$

ns ns ns $2.2(0.048)$

$0.3(0.001) \quad$ ns ns ns

$0.4(0.032) \quad n s \quad n s \quad 2.6(0.023)$

ns $\quad 3.6(0.014) \quad$ ns

ns ns ns n

$0.5(0.000) \quad n s \quad n s \quad n s$

ns $\quad$ ns $\quad 0.5(0.004) \quad 3.8(0.004)$

ns

$2.2(0.0079) \quad \mathrm{ns} \quad \mathrm{ns}$

$2.4(0.0007) \quad$ ns

ns $\quad 0.5(0.009)$

ns $\quad 0.5(0.002) \quad n s$

ns

ns ns

ns ns

$11.4(0.005) \quad n s$

$6.5(0.0000) \quad n s$ ns ns ns

ns ns ns

ns ns

$0.4(0.021) \quad n s \quad n s$

ns $\quad 2.4(0.005) \quad n s$

$4.0(0.018) \quad n s \quad n s$

$10.0(0.0004)$ ns ns

$4.0(0.0023) \quad$ ns ns ns ns ns 


\begin{tabular}{|c|c|c|c|c|c|}
\hline & \multicolumn{2}{|c|}{$\begin{array}{l}\text { Stressed } \\
\text { Drought }\end{array}$} & \multicolumn{2}{|c|}{$\begin{array}{l}\text { Stressed } \\
\text { Salt }\end{array}$} & \multirow{2}{*}{$\begin{array}{l}\text { Non-stressed } \\
\text { Controls } \\
\text { CN-fed/CN-fix }\end{array}$} \\
\hline & DN-fed/CN-fed & DN-fix/CN-fix & SN-fed/CN-fed & SN-fix/CN-fix & \\
\hline \multicolumn{6}{|l|}{ 19.10 Tetrapyrrole synthesis } \\
\hline G7IK85 Mg-chelatase subunit chll & $0.3(0.0002)$ & $0.3(0.0005)$ & ns & $0.5(0.004)$ & ns \\
\hline \multicolumn{6}{|l|}{ 20.1 Stress.biotic } \\
\hline BORZH7 putative thaumatin-like protein & ns & $0.4(0.000)$ & ns & ns & $2.2(0.001)$ \\
\hline G7IYL0 receptor-like protein kinase & ns & $0.5(0.002)$ & ns & ns & ns \\
\hline \multicolumn{6}{|l|}{ 20.2 Stress.abiotic } \\
\hline Q2HT97 heat shock protein Hsp70 & ns & ns & ns & $0.5(0.034)$ & ns \\
\hline G7JGC6 low-temperature inducible & $2.3(0.0001)$ & ns & ns & ns & $2.3(0.001)$ \\
\hline G7JGC9 low-temperature inducible & ns & ns & ns & $0.3(0.021)$ & ns \\
\hline \multicolumn{6}{|l|}{ 21.5 Redox.peroxiredoxin } \\
\hline G7JS60 peroxiredoxin Q & $2.6(0.0000)$ & ns & ns & ns & ns \\
\hline \multicolumn{6}{|c|}{ 23.4 Nucleotide metabolism.phosphotransfer and pyrophosphatases } \\
\hline G7JMM2 nucleoside diphosphate kinase & ns & ns & $2.0(0.040)$ & ns & ns \\
\hline B7FIM7 soluble inorganic pyrophosphatase & ns & $03(0.006)$ & ns & ns & ns \\
\hline \multicolumn{6}{|l|}{ 26.20 Misc.ferredoxin-like } \\
\hline G7KWY5 ferredoxin & ns & $0.3(0.011)$ & ns & ns & $2.1(0.037)$ \\
\hline \multicolumn{6}{|l|}{ 26.4 Misc.beta-1,3 glucan hydrolases } \\
\hline G7JQL4 endo-beta-1,3-glucanase & ns & ns & $0.5(0.014)$ & ns & ns \\
\hline \multicolumn{6}{|l|}{ 27.1 RNA.processing } \\
\hline G7JK09 Poly(A)-binding protein & ns & $0.4(0.000)$ & ns & ns & ns \\
\hline \multicolumn{6}{|l|}{ 27.4 RNA.RNA binding } \\
\hline G7JG67 glycerine-rich RNA binding protein & $0.5(0.0059)$ & ns & ns & ns & ns \\
\hline \multicolumn{6}{|l|}{ 29.2 Protein.synthesis } \\
\hline Q945F4 eukaryotic translation initiation factor 5A-2 & ns & $0.4(0.003)$ & ns & ns & $2.5(0.003)$ \\
\hline G7IH13 elongation factor EF-2 & ns & ns & ns & $2.5(0.000)$ & ns \\
\hline \multicolumn{6}{|l|}{ 29.5 Protein.degradation } \\
\hline G7LITO ATP-dependent Clp protease & $0.4(0.0226)$ & ns & ns & ns & ns \\
\hline G7ZVC0 presequence protease & ns & $0.5(0.010)$ & ns & ns & ns \\
\hline G7K8J5 bi-ubiquitin & ns & ns & $0.3(0.024)$ & ns & ns \\
\hline G7LB82 proteasome subunit alpha type & ns & ns & $2.1(0.019)$ & ns & ns \\
\hline \multicolumn{6}{|l|}{31.1 'Cell.organization } \\
\hline G7IAN2 tubulin ßchain & ns & ns & $5.4(0.0006)$ & ns & ns \\
\hline G7L5V0 tubulin ßchain & ns & ns & $3.0(0.0205)$ & $0.4(0.046)$ & ns \\
\hline G7KB73 annexin & $2.0(0.0394)$ & ns & ns & ns & $0.5(0.000)$ \\
\hline G7JAX5 actin & ns & ns & $3.8(0.0001)$ & ns & ns \\
\hline \multicolumn{6}{|l|}{ 34.1 Transport. p- and v-ATPases } \\
\hline A6Y950 Vacuolar H +-ATPase B subunit & ns & $0.5(0.001)$ & ns & ns & ns \\
\hline \multicolumn{6}{|c|}{ “PUTATIVE” UNCHARACTERIZED PROTEINS } \\
\hline $\begin{array}{l}\text { B7FJY9 similar 94.0\% Q9SOL2, CB24_PEA, chlorophyll a-b binding } \\
\text { protein P4, chloropl., Pisum sativum (garden pea), e=1.0 } \times 10^{-178}\end{array}$ & $3.0(0.0001)$ & ns & ns & ns & ns \\
\hline $\begin{array}{l}\text { B7FMC4 similar 73.0\% Q03666, GSTX4_TOBAC, probable } \\
\text { glutathione } S \text {-transferase, Nicotiana tabacum (common tobacco), } \\
e=1.0 \times 10^{-121}\end{array}$ & $2.1(0.007)$ & ns & ns & ns & $2.6(0.036)$ \\
\hline $\begin{array}{l}\text { B7FJR8 similar } 83.0 \% \text { Q9LZG0, ADK2_ARATH, adenosine kinase } \\
\text { 2, Arabidopsis thaliana (mouse-ear cress), } e=0\end{array}$ & ns & $0.4(0.000)$ & ns & ns & $2.1(0.015)$ \\
\hline $\begin{array}{l}\text { B7FM78 similar 97.0\% P81406, GAPN_PEA, NADP-dependent } \\
\text { glyceraldehyde-3-phosphate dehydrogenase, Pisum sativum } \\
\text { (garden pea), } e=0\end{array}$ & ns & $0.5(0.023)$ & ns & ns & ns \\
\hline
\end{tabular}




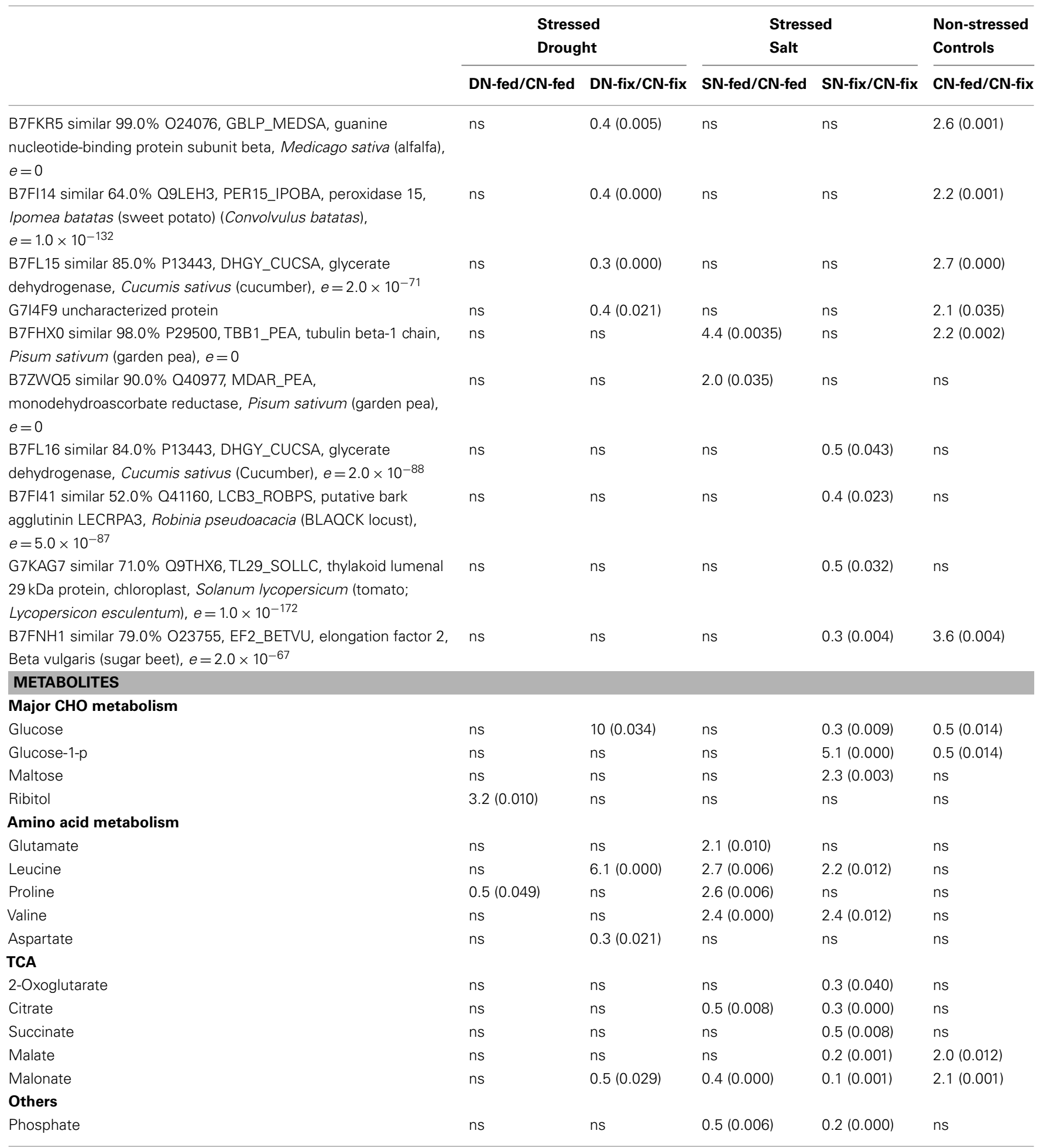

(Student's t test $p<0.05$ in brackets and fold change $\geq 2 ; n=6$ ) with significantly altered abundances in response to spectral counts of stress proteins and peak area of metabolites (IS and DW normalized). Protein category headers including binning numbers of the MapMan mapping file. CN-fed, control, N-fertilized; CN-fix,

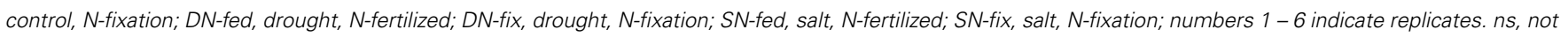
significant; SAMS, S-adenosylmethionone synthetase. 
not previously contained in the mapping were added. Separate bins were created for S. meliloti and S. medicae. Identified and pertinent protein accessions of these two endosymbionts were manually classified and thus put into sub-bins. The mapping file can be downloaded at http://www.univie.ac.at/mosys/databases.html. It will be updated in accordance to novel identifications/insights.

\section{FUNCTIONAL CHARACTERIZATION OF STRESS RESPONSIVE PUTATIVE UNCHARACTERIZED PROTEINS}

For a functional characterization of the stress responsive, so far putative proteins of unknown function in our analysis, we have used BLAST to find entries in phylogenetically related organisms by sequence similarity (see also Table 3 ).

\section{RESULTS \\ PHYSIOLOGICAL RESPONSES TO SALT AND DROUGHT IN $M$. TRUNCATULA}

Medicago truncatula was chosen in order to study the early stress acclimation under two $\mathrm{N}$-nutritional conditions combined with two different environmental perturbations (four different stress treatments). The effect of reduced water availability on plant performance was analyzed in order to assess the degree of stress as alterations in water status in both nutritional phenotypes in $M$. truncatula (N-fed and N-fix; Table 1). The effect of drought stress was significant for most of the analyzed parameters depending on nutritional status. Water potential was significantly reduced during drought (potential dropped to $-0.98 \mathrm{MPa}$ and $-1.06 \mathrm{MPa}$ for $\mathrm{N}$-fix and $\mathrm{N}$-fed plants respectively), but not during salt stress. The PSII operating efficiency in terms of $\left(F^{\prime} \mathrm{q} / F^{\prime} \mathrm{m}\right)$ was significantly decreased only in the leaves of drought stressed $\mathrm{N}$-fed plants. Stomatal conductance was significantly reduced upon perturbation. In order to get a more holistic insight into the extent of plant acclimatory responses, significantly changing root metabolites were assessed (Table 2). Most of the significantly changed metabolites in roots did not change significantly in the leaves and vice versa. However, the degree of stress in terms of the fold change was more significant in the roots. Most of the responsive metabolites increased during stress. However, especially organic acids and a few amino acids of the leaves showed a decline in response to stress (Table 3).

\section{DESCRIPTIVE ANALYSIS OF THE DETECTED PROTEINS AND METABOLITES}

All identified proteins and metabolites were functionally categorized and visualized with Mapman (Thimm et al., 2004) using a new $M$. truncatula mapping file we created for UniProt data (Figure 1, see Mapman Mapping File for M. truncatula Proteins and Metabolites). Upon all identified proteins (643), "protein regulation" (20\%), and "PS" (13\%) are the dominant functional categories. In addition, the proteins assigned to the PS show highest relative abundance (spectral count per protein weight). Other categories are "redox," "amino acid," and "cell," each accounting for $5 \%$ of all identified proteins. Stress and signaling together reach $7 \%$ of all protein identifications followed by several other small categories (Figure 1). For the metabolites we found the major categories of the primary metabolism including amino acids "AA metabolism," the "TCA" cycle (organic acids), sugars "major $\mathrm{COH}$ metabolism," and "others."

\section{QUANTITATIVE DATA MINING FOR SALT AND DROUGHT RESPONSIVE METABOLITES AND PROTEINS OF NUTRITIONAL M. TRUNCATULA PHENOTYPES}

About $11 \%$ of all identified proteins (69 of 643 ) and $33 \%$ of all identified metabolites (15 of 45) changed significantly upon early stress acclimation $(p \leq 0.05$ and fold change $\geq 2 ; n=6)$. GC-MS based metabolite profiling generally results in the identification of metabolites associated with the primary metabolism. Here, we found that most metabolites responding to stress were corresponding to the major sugar and amino acid metabolism and the TCA cycle. The protein categories with the highest percentage involved in stress response are: "PS," "amino acid," and "cell" with $12 \%$ each (Table 3). A small overlap of responsive compounds across the two stress treatments was observed ( 7 of 98, Figure 2). However, no analyzed compound was responsive during stress acclimation across all treatments. The Mg-chelatase subunit chlI (G7IK85), leucine, and malonate have been found to respond to three of the four different treatments. Of all the significantly altered levels of proteins and metabolites, only a particular subset responded to a specific treatment. Approaching the data from a different perspective, Figure 2A shows that more responsive compounds are shared between the salt than between the drought treated phenotypes. In contrast, a few specific response features were observed when dissecting the nutritional phenotypes (Figure 2B). Altogether, we found that the majority of significantly changed compounds of the nitrogen fertilized ( $\mathrm{N}$-fed) plants increased while the majority of significantly changed compounds of the N-fix plants decreased independent of the stress type (Figures 3 and 4 ).

We then compared the control levels of the proteins of the nutritional phenotypes with the response levels of perturbation (Figure 4). Interestingly, for the drought stressed plants, an approximation in protein levels between the two phenotypes has been observed. Thirteen responsive proteins of the N-fix plants show a higher control level compared to the $\mathrm{N}$-fed controls. At the analyzed time of drought acclimation, those proteins decreased significantly, reaching the level of the $\mathrm{N}$-fed plants (which have not changed during drought stress). Vice versa, control levels of six responsive proteins of the $\mathrm{N}$-fed plants increased during drought, reaching unchanged control levels of the $\mathrm{N}$-fix plants. This mechanism is less distinct for salt stress (Figure 4).

\section{DISCUSSION \\ DEFINITION OF THE DEGREE OF STRESS AND THE CHALLENGE OF COMPARING DIFFERENT CONSTRAINTS}

Salt and drought, two major environmental constraints have been compared. A moderate stress level was applied in order to study the early acclimation responses of $M$. truncatula growing under two different nutritional conditions. A biphasic growth inhibition model by saline conditions has been proposed earlier (Munns, 2002). During the first phase, growth inhibition is mainly governed by the decreased water availability due to higher solute concentrations in the soil solution, lowering soil water potential. If salt stress is prolonged ion toxicity effects gain importance in constraining plant metabolism and survival, described as the second phase, the salt stress specific phase (Sanchez et al., 2008a). To obtain similar early stress response levels for both stress types, keeping morphological parameters comparable, plants were harvested at the same 


lightreaction
photorespiration
Calvin cycle

FIGURE 1 | Mapman overview. Functional distribution and relative abundance of the 643 shoot proteins ( $\log 10$ of the spectral count normalized by protein weight; FDR $\leq 0.01 \%$ ) and 45 metabolites (Log10 of peak area normalized by DW and IS) identified. Triangles = proteins; circles $=$ metabolites. The strength of the color indicates the abundance of the compounds.

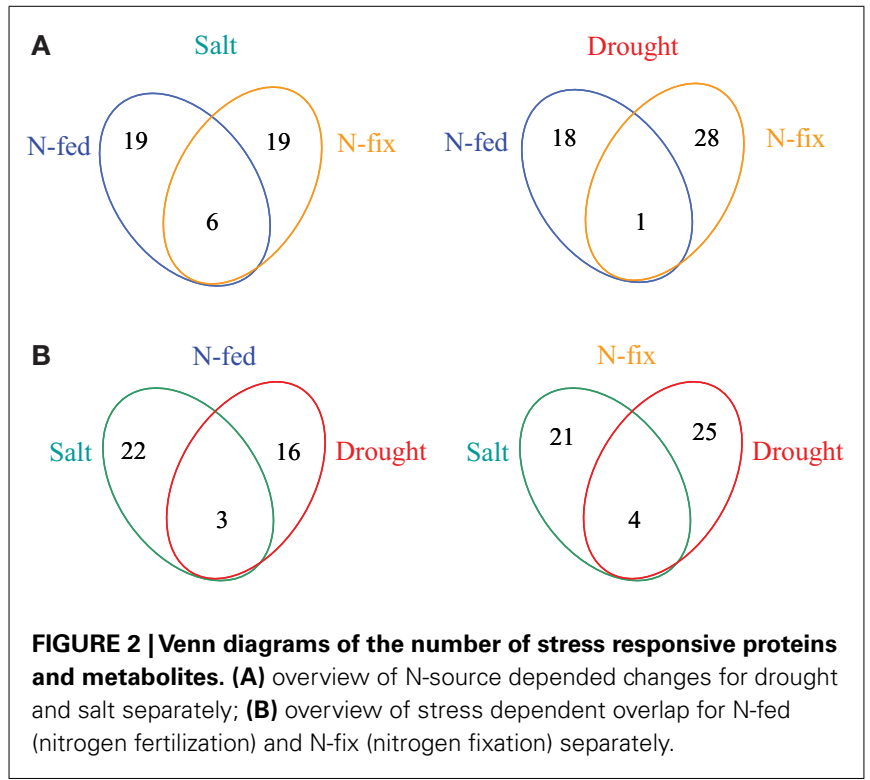

age (duration-of-stress was 6 days). We compared the response of M. truncatula to water deficit resulting from a progressive mild drought treatment and a high initial $200 \mathrm{mM}$ salt treatment. After 6 days of treatment, water-withholding and salt stress treatment resulted in stress responses. In order to assess the degree of stress at the plant level, several physiological parameters showing typical responses to decreasing water availability were analyzed as direct and indirect measures of plant water status (Table 1). All four stress treatments elicited acclimatory responses, as evidenced by

\section{DN-fed vs CN-fed ( $5 \downarrow, 14 \hat{\imath})$

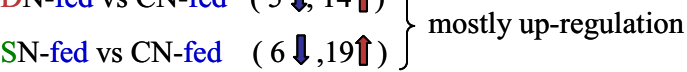 \\ $\left.\begin{array}{ll}\mathrm{DN}-\text {-fix vs CN-fix } & (26 \rrbracket, 3 \Uparrow) \\ \mathrm{SN}-\text {-fix vs CN-fix } & (18 \downarrow, 7 \Uparrow)\end{array}\right\}$ mostly down-regulation \\ CN-fix vs CN-fed $(4 \downarrow, 21 \Uparrow)$ comparison of basic control states \\ FIGURE 3 | Summary of the number of up- or down-regulated shoot compounds (proteins and metabolites) of the different treatments. \\ Compounds, mostly up-regulated in $\mathrm{N}$-fed and mostly down-regulated in $\mathrm{N}$-fix plants during stress (independent on stress condition). D, drought; $\mathrm{C}$, control; S, salt; $\mathrm{N}$-fed, nitrogen fertilization; $\mathrm{N}$-fix, nitrogen fixation.}

significant decreases in stomatal conductance. Furthermore, our data also indicate that stress treatments had a low effect on photosynthesis. The PSII operating efficiency was neither affected by salt nor severely by drought (Table 1). This supports the onset of an early phase of stress acclimation. Drought experiments of soybean have shown that rates of photosynthesis were inhibited when leaf water potential dropped below -1.1 MPa (Boyer, 1970). This is consistent with our data; since photosynthesis was only affected in drought treated $\mathrm{N}$-fed plants, when leaf water potential reached threshold. Salt and drought constraints are initially encountered at the root part of the plants. This might also contribute to the fact that in legumes, $\mathrm{N}$-fixation is impaired in response to water deficit, before a decrease in photosynthetic rate can be observed (Durand et al., 1987; Djekoun and Planchon, 1991). As expected, when testing for some significant changes of metabolites in roots compared to the shoots (Table 2), the extent of stress-induced was more 


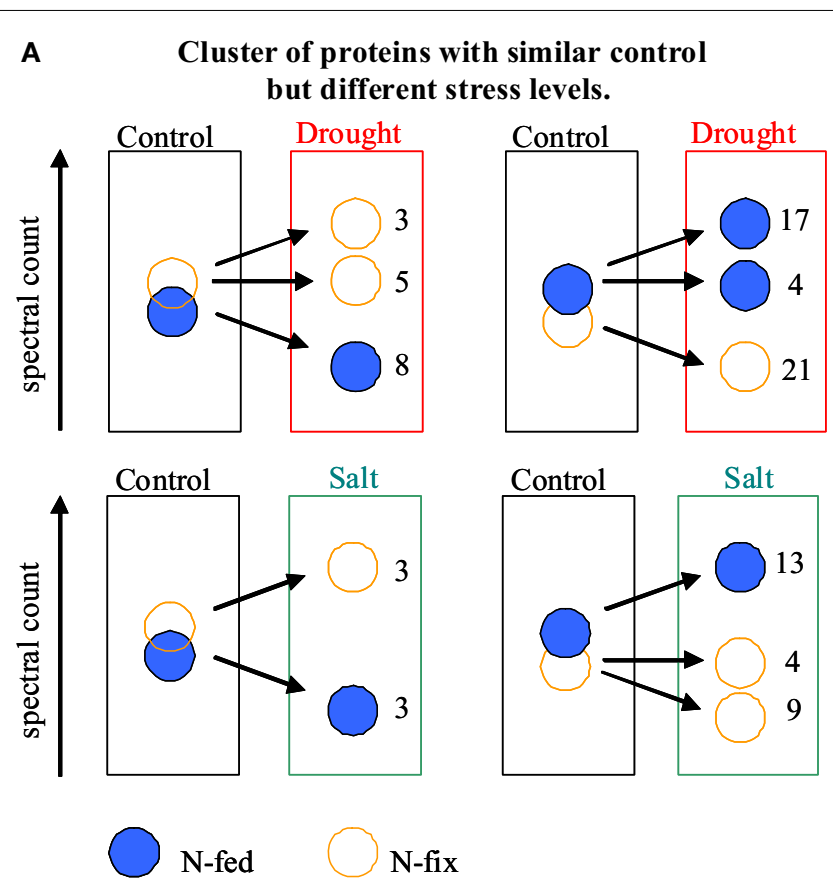

B Cluster of proteins with different control levels (N-fix always higher) but similar stress levels.
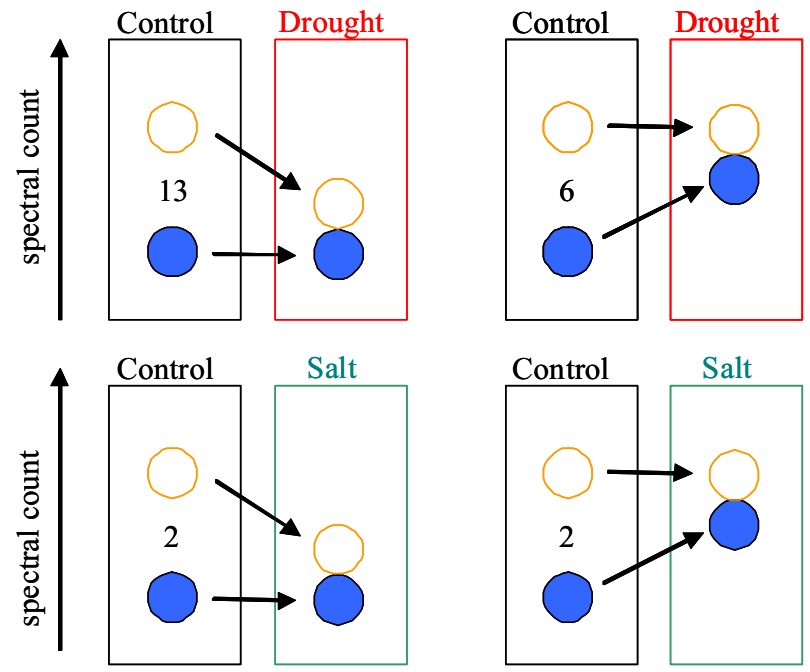

N-fed

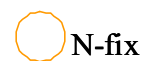

FIGURE 4 | Schematic overview of differentially up or down-regulated protein clusters depending on control level and nutritional status. (A) Similar control levels but different stress levels. (B) Different control levels but similar stress response levels. $\mathrm{N}$-fed, nitrogen fertilization; N-fix, nitrogen fixation.

important in roots than in shoots. Some typical stress response marker such as proline, GABA and the polyols pinitol, ononitol, and myo-inositol (Vernon and Bohnert, 1992) were partially found to solely or more distinctly accumulate in the roots. Surprisingly, proline was only significantly increased in roots ( $\sim 10$-fold $)$ exposed to drought and shoots ( $\sim$ twofold) exposed to salt. In leaves of $\mathrm{N}$-fed plants it was found to even decrease. Since proline has been reported to increase during drought (Delauney and Verma, 1993) and other abiotic effects (Szabados and Savouré, 2010), the data suggest a moderate stress response where proline accumulation has not been fully established. This observation could result from the more pronounced stomatal closure in salt stressed than in drought stressed plants. As the water loss through stomata is lower, tissue WC, and water potential remain constant. Thus the degree of stress at the plant tissue level might not yet induce a substantial accumulation of osmoprotectants such as proline. The results for drought are in agreement with the data of Filippou et al. (2011), where, e.g., proline accumulation in $M$. truncatula leaves occurred only after 9 days of water-withholding, whereas in roots already after 3 days. The biological role of proline accumulation during stress is under extensive discussion (Verbruggen and Hermans, 2008). Drought stress experiments in Lotus japonicus strengthened the hypothesis that proline is necessary for the rehydration ability of the plants (Diaz et al., 2010). In agreement with our data, they showed that it does not reduce the rate of water loss. Interestingly, the counter-correlation of salt stressed plants showing no changes in leaf water potential suggests that this might be due to the more significant decrease in stomatal conductance, regulated by an increased ABA level. It was shown that the stomatal conductance was controlled by the root water potential when the ABA level of the xylem sap was increased (Tardieu et al., 1991). Thus our data demonstrate that salt and drought have impact on stomatal conductance but to a different degree, indicating higher stress response to salt than to drought. In contrast, water potential decreased significantly only during drought and more severely in $\mathrm{N}$-fed compared to $\mathrm{N}$-fix plants leading to the conclusion that drought stress has a stronger and thus earlier impact on water availability than salt. However, effects are still in a moderate range revealing an early stress response for both constraints. Altogether the physiological results lead to the following conclusions: (a) Indifferent to stress treatment and nutritional status stomatal conductance is an early stress response parameter; (b) Proline and the other observed, typical stress responsive metabolites as well as photosynthetic efficiency seem to be robust markers only for severe stress in leaves; (c) the root is the first place adjusting and controlling acclimation of stress; (d) all physiological parameters showing significant differences when comparing control to stressed groups, interestingly also showing significant differences between the two stress treatments; (e) in order to establish the highest possible similarity in plant water status between the two constraints, numerous salt concentrations and time points need to be assessed (and possibly additional parameters measured). However, an identical response seems very unlikely.

\section{MOLECULAR STRESS ADJUSTMENTS DEPENDING ON THE NUTRITIONAL PHENOTYPE - CHAOS WITH SYSTEM?}

Numerous studies on salt and/or drought stress in plants have been summarized recently (Pinheiro and Chaves, 2011; Krasensky and Jonak, 2012). Drought and salinity reduce soil water availability and induce common stress avoidance strategies such as shoot growth inhibition and lower stomatal conductance. However, there is not much overlap between the molecular data sets 
published so far. This is probably due to the fact that experimental setups and application of stresses are very different and an appropriate definition of the degree of stress (in terms of experimental conditions as well as plant water status) for a better comparison is difficult and often missing (Jones, 2007). Another reason may be the differential steady-state of the plants such as growth state (Chaves et al., 2009) and nutritional status prior to stress exposure (Frechilla et al., 2000). The molecular data presented here shows that salt and drought stress share few common features in terms of changes in compound abundance (Table 3 and Figures 2A,B). First of all, the significantly responding compounds appear randomly distributed across treatments and most functional categories of the metabolic network. This result is not surprising since stress effects seem not severe and plant metabolism has not yet been fully adjusted at the time of analyses. However, in agreement with other data (Sanchez et al., 2008a,b), we found a down-regulation of organic acids and an up-regulation of amino acids that seem typical for salt stress (Table 3 ). The results suggest that the TCA cycle is almost exclusively responding to early salt stress but not to drought. Within the N-fix phenotype of the salt stress group all five of the responsive metabolites of the TCA cycle were down-regulated.

Amino acids most significantly change in salt stressed and $\mathrm{N}$-fed plants while most of the responsive sugars significantly changed in N-fix plants. The protein levels of the functional categories of amino acid and N-metabolism decreased, while the amino acids accumulated in response to stress. This trend could be observed within all stress treatments, except for drought stressed $\mathrm{N}$-fed plants where this trend was inverted (Table 3). Possibly, increased amino acid levels are the cause for the down-regulation of proteins involved in amino acid synthesis and/or the consequence of protein degradation. Interestingly, this correlation has also previously been observed in root nodules of drought stressed M. truncatula (Larrainzar et al., 2009). They also found some glutamine sythetase isoforms decreasing during drought. However, while amino acid synthetases and asparagine aminotransferases seemed to play an important role during drought stress acclimation in nodules, $S$ adenosyl-L-methionine synthases (SAMS) seem to be more specifically involved in leaves. In addition, the SAMS isoforms seem only involved in early response to drought but not to salt stress. Furthermore, the four identified SAMS isoforms respond differently to drought. SAMS is a key enzyme, catalyzing the biosynthesis of SAM using methionine and ATP. It has been described that some of the SAMS genes were expressed constitutively, whereas others seemed specifically regulated by developmental and/or environmental factors depending on the requirement for SAM (Boerjan et al., 1994; Gómez-Gómez and Carrasco, 1998). SAM is a methyl donor, involved in many regulatory relevant processes on the transcript and protein level (Gómez-Gómez and Carrasco, 1998). However, further studies need to be conducted to unravel the regulatory function of the different SAMS isoforms during plant responses to water deficits.

Sugars are usually described to increase during osmotic stress adjustment (Clifford et al., 1998; Hummel et al., 2010). Surprisingly, glucose was decreasing in salt stressed plants. However, under drought stress glucose increased and other carbon metabolites increased as well. Interestingly, on the protein level, cell organization seemed most responsive in salt stressed $\mathrm{N}$-fed plants. Distinctively, the two tubulin $\beta$ chains (G7IAN2 and G7L5V0) and actin (G7JAX5) were found to be up-regulated. These components are involved in the dynamics of the cytoskeleton. Several studies in Arabidopsis have shown a relationship between the plant cytoskeleton and salt stress tolerance by the induction of actin filament assembly and bundle formation (Wang et al., 2010, 2011). This result may indicate a more specific response of salt stressed plants that are $\mathrm{N}$-fertilized.

Besides malonate (down-regulation) and leucine (upregulation), the metabolites found to respond in three out of the four treatments, Mg-chelatase subunit chlI (G7IK85) was also significantly changed (down-regulated) in both drought phenotypes as well as the salt stressed $\mathrm{N}$-fix plants. The Mg-chelatase, composed of three different subunits, is the first enzyme involved in chlorophyll biosynthesis. It has been described to be involved in several stress-induced alterations. Dalal and Tripathy (2012) summarized the stress response of enzyme activity and on the protein and transcript level. They showed that $\mathrm{Mg}$-chelatase protein abundance and gene expression are generally down-regulated during drought, salt, cold, and heat stress. A study on pea revealed that the Mg-chelatase chlI activity is redox regulated by chloroplast thioredoxins (Luo et al., 2012). Intriguingly, there are controversial discussions dealing with the $\mathrm{Mg}$-chelatase subunit chlH. Initially it has been reported to act as an ABA receptor (Shen et al., 2006). However, Müller and Hansson (2009) reported that ABA had no effect on subunit chlH. Recently, Tsuzuki et al. (2011) presented evidence for the chlH subunit affecting ABA signaling of stomata guard cells but not acting as ABA receptor. These data strongly support that the Mg-chelatase is an important key player of chlorophyll degradation already during early stress response. The role of subunit chli, however, needs to be studied in more detail.

Most other stress responsive compounds found, appear to be selectively distributed. However, we found interesting response patterns that might be explained by regulatory important mechanism: noticeably, the ratio between up and down-regulated compounds is grouping the nutritional phenotypes (Figure 3). The different molecular control levels of the two nutritional traits are leading to these response patterns. Starting with the comparison of the phenotypes, we found 25 of the stress responsive compounds also significantly distinguish $\mathrm{N}$-fix from $\mathrm{N}$-fed plants under control condition (Table 3). Here in general, protein and metabolite levels are higher in the control steady states of the $\mathrm{N}$ fix plants compared to the $\mathrm{N}$-fed plants. Furthermore, the ratio of up- vs. down-regulated proteins and metabolites during early stress response is generally higher in $\mathrm{N}$-fed plants and vice versa the ratio of down-regulation higher in $\mathrm{N}$-fed plants. Several distinct proteins seemed to change randomly coming from the same control state (Figure 4A). However, when analyzing the phenotypes after early stress adjustment, the proteomic data revealed a process of approximation to a similar molecular stress-steady-state (Figure 4B). Especially the protein response-pattern to drought aligned the way that proteins of the $\mathrm{N}$-fix shoots of higher control level decreased to the level of $\mathrm{N}$-fed shoots and vice versa. Taking these data together, there is evidence that the $\mathrm{N}$-fed plants invest more energy in stress adjustment of protein levels than the $\mathrm{N}$ fixing plants, where down-regulation of proteins is dominating the 
process of acclimation. Interestingly, there is an overlap of six for the salt- compared to one stress responsive protein of the drought treatment (Figure 2A). Thus, salt stress response seems less dependent on the nutritional status than drought. Thus, we propose that (a) the initial molecular steady-state of the plants in terms of nutritional status seems pivotal for the downstream stress adjustment strategy; (b) during stress-acclimation-phase plants try to adjust their metabolic network to an approximate level (more significantly during the drought stress response); and (c) N-fix plants may need less energy for the stress adjustment than $\mathrm{N}$-fed $M$. truncatula plants.

\section{CONCLUSION}

In the case of M. truncatula, our results suggest the following.

- Our drought stress treatment, led to a more pronounced water deficiency at the plant level than the salt stress treatment. This finding points to stress type specific acclimation strategies, especially stress avoidance mechanisms such as stomatal conductance. Either way, physiological, metabolomic,

\section{REFERENCES}

Aguirrezabal, L., Bouchier-Combaud, S., Radziejwoski, A., Dauzat, M., Cookson, S. J., and Granier, C. (2006). Plasticity to soil water deficit in Arabidopsis thaliana: dissection of leaf development into underlying growth dynamic and cellular variables reveals invisible phenotypes. Plant Cell Environ. 29, 2216-2227.

Aranjuelo, I., Molero, G., Erice, G., Christophe Avice, J., and Nogues, S. (2011). Plant physiology and proteomics reveals the leaf response to drought in alfalfa (Medicago sativa L.). J. Exp. Bot. 62, 111-123.

Baker, N. R. (2008). Chlorophyll fluorescence: a probe of photosynthesis in vivo. Annu. Rev. Plant Biol. 59, 89-113.

Bianco, C., and Defez, R. (2009). Medicago truncatula improves salt tolerance when nodulated by an indole-3-acetic acid-overproducing Sinorhizobium meliloti strain. J. Exp. Bot. 60, 3097-3107.

Boerjan, W., Bauw, G., Van Montagu, M., and Inzé, D. (1994). Distinct phenotypes generated by overexpression and suppression of Sadenosyl-L-methionine synthetase reveal developmental patterns of gene silencing in tobacco. Plant Cell 6, 1401-1414.

Boyer, J. S. (1970). Differing sensitivity of photosynthesis to low leaf water potentials in corn and soybean. Plant Physiol. 46, 236-239.

Chaves, M. M., Flexas, J., and Pinheiro, C. (2009). Photosynthesis under drought and salt stress: regulation mechanisms from whole plant to cell. Ann. Bot. 103, 551-560.
Clifford, S., Arndt, S., Corlett, J., Joshi, S., Sankhla, N., Popp, M., et al. (1998). The role of solute accumulation, osmotic adjustment and changes in cell wall elasticity in drought tolerance in Ziziphus mauritania (Lamk.). J. Exp. Bot. 49, 967-977.

Dalal, V. K., and Tripathy, B. C. (2012). Modulation of chlorophyll biosynthesis by water stress in rice seedlings during chloroplast biogenesis*. Plant Cell Environ. 35, 1685-1703.

Delauney, A. J., and Verma, D. P. S. (1993). Proline biosynthesis and osmoregulation in plants. Plant J. 4, 215-223.

Diaz, P., Betti, M., Sanchez, D. H., Udvardi, M. K., Monza, J., and Marquez, A. J. (2010). Deficiency in plastidic glutamine synthetase alters proline metabolism and transcriptomic response in Lotus japonicus under drought stress. New Phytol. 188, 1001-1013.

Djekoun, C., and Planchon, A. (1991). Water status effect on dinitrogen fixation and photosynthesis in soybean. Agron. J. 83, 316-322.

Durand, J. L., Sheehy, E. J., and Minchin, F. R. (1987). Nitrogenase activity, photosynthesis and nodule water potential in soyabean plants experiencing water deprivation. J. Exp. Bot. 38, 311-321.

Evans, H. J. (1981). "Symbiotic nitrogen fixation in legume nodules," in Research Experiences in Plant Physiology, ed. T. C. Moore (New York: Springer-Verlag), 294-310. los, V. (2011). Effect of drought
Filippou, P., Antoniou, C., and Fotopou-

and proteomic data revealed significant differences in the degree and strategy of early drought, as compared to salt stress response, under identical growth conditions.

- Mg-chelatase subunit chlI, leucin, and malonate were significantly affected in three out of four stress treatments (two stress types, two nutritional conditions). Thus, they are likely robust early stress response markers. Further evaluation studies are necessary for confirmation.

- Proteomic adjustment seems low cost for $\mathrm{N}$-fixing, as compared to $\mathrm{N}$-fertilized plants, suggesting a potentially increased tolerance to stress. Whether this can be explained by symbiotic interaction itself or a more general kind of nutritional priming remains to be investigated further. However our results underline that the $\mathrm{N}$-nutritional condition seems of crucial importance for plant stress acclimation.

\section{ACKNOWLEDGMENTS}

Vlora Mehmeti, Christiana Staudinger, and David Lyon were funded by the Austrian Fonds zur Förderung der wissenschaftlichen Forschung" (FWF), P23441-B20.

and rewatering on the cellular status and antioxidant response of $\mathrm{Med}$ icago truncatula plants. Plant Signal. Behav. 6, 270-277.

Frechilla, S., Gonzalez, E. M., Royuela, M., Minchin, F. R., Apaicio-Tejo, P. M., and Arrese-Igor, C. (2000). Source of nitrogen nutrition (nirogen fixation or nitrate assimilation) is a major factor involved in pea response to moderate water stress. J. Plant Physiol. 157, 609-617.

Gibon, Y., Blasing, O. E., Palacios-Rojas, N., Pankovic, D., Hendriks, J. H., Fisahn, J., et al. (2004). Adjustment of diurnal starch turnover to short days: depletion of sugar during the night leads to a temporary inhibition of carbohydrate utilization, accumulation of sugars and post-translational activation of ADP-glucose pyrophosphorylase in the following the light period. Plant J. 39, 847-862.

Gibon, Y., Usadel, B., Blaesing, O. E., Kamlage, B., Hoehne, M., Trethewey, R., et al. (2006). Integration of metabolite with transcript and enzyme activity profiling during diurnal cycles in Arabidopsis rosettes. Plant Cell Environ. 32, 859-874.

Gómez-Gómez, L., and Carrasco, P. (1998). Differential expression of the S-adenosyl-L-methionine synthase genes during pea development. Plant Physiol. 117, 397-405.

Hajduch, M., Hearne, L. B., Miernyk, J. A., Casteel, J. E., Joshi, T., Agrawal, G. K., et al. (2010). Systems analysis of seed filling in Arabidopsis: using general linear modeling to assess concordance of transcript and protein expression. Plant Physiol. 152, 2078-2087.

Hoehenwarter, W., and Wienkoop, S. (2010). Spectral counting robust on high mass accuracy mass spectrometers. Rapid Commun. Mass Spectrom. 24, 3609-3614.

Hummel, I., Pantin, F., Sulpice, R., Piques, M., Rolland, G., Dauzat, M., et al. (2010). Arabidopsis plants acclimate to water deficit at low cost through changes of carbon usage: an integrated perspective using growth, metabolite, enzyme, and gene expression analysis. Plant Physiol. 154, 357-372.

IPCC. (2007). Fourth Asessment Report: Synthesis Report. Available at: http://ipcc.ch/publications_and_ data/ar4/syr/en/contents.html.

Jogaiah, S., Govind, S. R., and Tran, L.-S. P. (2012). Systems biologybased approaches toward understanding drought tolerance in food crops. Crit. Rev. Biotechnol. 1-17. doi:10.3109/07388551.2012.659174

Jones, H. G. (2007). Monitoring plant and soil water status: established and novel methods revisited and their relevance to studies of drought tolerance. J. Exp. Bot. 58, 119-130.

Kang, Y., Han, Y., Torres-Jerez, I., Wang, M., Tang, Y., Monteros, M., et al. (2011). System responses to longterm drought and re-watering of two contrasting alfalfa varieties. Plant J. 68, 871-889.

Krasensky, J., and Jonak, C. (2012). Drought, salt, and temperature stress-induced metabolic rearrangements and regulatory networks. $J$. Exp. Bot. 63, 1593-608. 
Larrainzar, E., Wienkoop, S., Scherling, C., Kempa, S., Ladrera, R., Arrese-Igor, C., et al. (2009). Carbon metabolism and bacteroid functioning are involved in the regulation of nitrogen fixation in Medicago truncatula under drought and recovery. Mol. Plant Microbe Interact. 22, 1565-1576.

Larrainzar, E., Wienkoop, S., Weckwerth, W., Ladrera, R., Arrese-Igor, C., and Gonzalez, E. M. (2007). Medicago truncatula root nodule proteome analysis reveals differential plant and bacteroid responses to drought stress. Plant Physiol. 144, 1495-1507.

Levitt, J. (1980). "Responses of plants to environmental stresses," in Water, Radiation, Salt and Others Stresses. Vol. 2. New York: Academic Press.

Lopez, M., Herrera-Cervera, J. A., Iribarne, C., Tejera, N. A., and Lluch, C. (2008). Growth and nitrogen fixation in Lotus japonicus and Medicago truncatula under $\mathrm{NaCl}$ stress: nodule carbon metabolism. J. Plant Physiol. 165, 641-650.

Luo, T., Fan, T., Liu, Y., Rothbart, M., Yu, J., Zhou, S., et al. (2012). Thioredoxin redox regulates ATPase activity of $\mathrm{Mg}$ chelatase chlI subunit and modulates redox-mediated signaling in tetrapyrrole biosynthesis and homeostasis of reactive oxygen species in pea plants. Plant Physiol. 159, 118-130.

Miransari, M., and Smith, D. L. (2009). Alleviating salt stress on soybean (Glycine max (L.) Merr.) - Bradyrhizobium japonicum symbiosis, using signal molecule genistein. Eur. J. Soil Biol. 45, 146-152.

Müller, A. H., and Hansson, M. (2009). The barley magnesium chelatase $150-\mathrm{kd}$ subunit is not an abscisic acid receptor. Plant Physiol. 150, 157-166.
Munns, R. (2002). Comparative physiology of salt and water stress. Plant Cell Environ. 25, 239-250.

Naya, L., Ladrera, R., Ramos, J., González, E. M., Arrese-Igor, C., Minchin, F. R., et al. (2007). The response of carbon metabolism and antioxidant defenses of alfalfa nodules to drought stress and to the subsequent recovery of plants. Plant Physiol. 144, 1104-1114.

Noreen, Z., and Ashraf, M. (2009). Assessment of variation in antioxidative defense system in salt-treated pea (Pisum sativum) cultivars and its putative use as salinity tolerance markers. J. Plant Physiol. 166, 1764-1774.

Pinheiro, C., and Chaves, M. M. (2011). Photosynthesis and drought: can we make metabolic connections from available data? J. Exp. Bot. 62, 869-882.

Rispail, N., Kaló, P., Kiss, G. B., Ellis, T. H. N., Gallardo, K., Thompson, R. D., et al. (2010). Model legumes contribute to faba bean breeding. Field Crops Res. 115, 253-269.

Salah, I., Albacete, A., Martínez Andújar, C., Haouala, R., Labidi, N., Zribi, F., et al. (2009). Response of nitrogen fixation in relation to nodule carbohydrate metabolism in Medicago ciliaris lines subjected to salt stress. J. Plant Physiol. 166, 477-488.

Sanchez, D. H., Lippold, F., Redestig, H., Hannah, M. A., Erban, A., Krämer, U., et al. (2008a). Integrative functional genomics of salt acclimatization in the model legume Lotus japonicus. Plant J. 53, 973-987.

Sanchez, D. H., Siahpoosh, M. R., Roessner, U., Udvardi, M., and Kopka, J. (2008b). Plant metabolomics reveals conserved and divergent metabolic responses to salinity. Physiol Plant 132, 209-219.

Shen, Y.-Y., Wang, X.-F., Wu, F.-Q., Du, S.-Y., Cao, Z., Shang, Y., et al. (2006). The Mg-chelatase $\mathrm{H}$ subunit is an abscisic acid receptor. Nature 443 823-826.

Szabados, L., and Savouré, A. (2010). Proline: a multifunctional amino acid. Trends Plant Sci. 15, 89-97.

Tardieu, F., Katerji, N., Bethenod, O., Zhang, J., and Davies, W. J. (1991). Maize stomatal conductance in the field: its relationship with soil and plant water potentials, mechanical constraints and ABA concentrations in the xylem sap. Plant Cell Environ. 53, 205-214.

Thimm, O., Bläsing, O., Gibon, Y., Nagel, A., Meyer, S., Krüger, P., et al. (2004). Mapman: a user-driven tool to display genomics data sets onto diagrams of metabolic pathways and other biological processes. Plant J. 37, 914-939.

Tsuzuki, T., Takahashi, K., Inoue, S. Okigaki, Y., Tomiyama, M., Hossain, M. A., et al. (2011). Mgchelatase $\mathrm{H}$ subunit affects ABA signaling in stomatal guard cells, but is not an ABA receptor in Arabidopsis thaliana. J. Plant Res. 124, 527-538.

Verbruggen, N., and Hermans, C. (2008). Proline accumulation in plants: a review. Amino Acids 35, 753-759.

Vernon, D. M., and Bohnert, H. J. (1992). A novel methyl transferase induced by osmotic stress in the facultative halophyte Mesembryanthemum crystallinum. EMBO J. 11, 2077-2085.

Verslues, P. E., Agarwal, M., KatiyarAgarwal, S., Zhu, J., and Zhu, J.K. (2006). Methods and concepts in quantifying resistance to drought, salt and freezing, abiotic stresses that affect plant water status. Plant J. 45, 523-539.

Wang, C., Zhang, L., Yuan, M., Ge, Y., Liu, Y., Fan, J., et al. (2010). The microfilament cytoskeleton plays a vital role in salt and osmotic stress tolerance in Arabidopsis. Plant Biol. (Stuttg.) 12, 70-78.
Wang, C., Zhang, L.-J., and Huang, R.-D. (2011). Cytoskeleton and plant salt stress tolerance. Plant Signal. Behav. 6, 29-31.

Wienkoop, S. (2011). "Proteomics and metabolomics for systems biology in legumes," in Cool Season Grain Legumes, eds M. Perez de la Vega, A. M. Torres, J. I. Cubero, and C. Kole (New Hampshire: Science Publishers), 303-314.

Wienkoop, S., Staudinger, C., Hoehenwarter, W., Weckwerth, W., and Egelhofer, V. (2012). ProMEX - a mass spectral reference database for plant proteomics. Front. Plant Sci. 3:125. doi:10.3389/fpls.2012.00125

Conflict of Interest Statement: The authors declare that the research was conducted in the absence of any commercial or financial relationships that could be construed as a potential conflict of interest.

Received: 11 October 2012; paper pending published: 18 October 2012; accepted: 30 November 2012; published online: 21 December 2012.

Citation: Staudinger C, Mehmeti V, Turetschek R, Lyon D, Egelhofer $V$ and Wienkoop $S$ (2012) Possible role of nutritional priming for early salt and drought stress responses in Medicago truncatula. Front. Plant Sci. 3:285. doi: 10.3389/fpls.2012.00285

This article was submitted to Frontiers in Plant Proteomics, a specialty of Frontiers in Plant Science.

Copyright ( $\odot 2012$ Staudinger, Mehmeti, Turetschek, Lyon, Egelhofer and Wienkoop. This is an open-access article distributed under the terms of the Creative Commons Attribution License, which permits use, distribution and reproduction in other forums, provided the original authors and source are credited and subject to any copyright notices concerning any third-party graphics etc. 